\title{
ANALISIS FAKTOR YANG MEMPENGARUHI PELAKSANAAN AUDIT BERBASIS TEKNOLOGI INFORMASI
}

\author{
Michelle Kristian dan Elsa Imelda \\ Fakultas Ekonomi Universitas Tarumanagara \\ Email: kapmichellekristian@gmail.com
}

\begin{abstract}
The purpose of this research is investigating the factors affecting to information system audit implemented by Auditor. The following factors consists of control risk determination by Auditor, the size of Public Accountant Firm, business complexity, information sysem complexity, time needed for performing the audit engagement, the number of asset and the number of revenue. This research was conducted by distributing kuesionairs to Auditor respondents working in Jakarta, both from big four and non big four. The data received is 46 of 50 respondents. The result testing form multiple regression indicated that one independent variable, i.e. time needed for performing the audit engagement, which affecting to information system audit implemented by Auditor.
\end{abstract}

Keywords: information system audit, risk determination, Public Accountant Firm, business complexity, information sysem complexity, time, the number of asset, the number of revenue.

\begin{abstract}
Abstrak: Tujuan dari penelitian ini adalah menganalisis faktor yang mempengaruhi audit sistem informasi dilaksanakan oleh Auditor. Faktor-faktor berikut terdiri dari kontrol penentuan risiko oleh Auditor, ukuran Kantor Akuntan Publik, kompleksitas bisnis, informasi kompleksitas sysem, waktu yang dibutuhkan untuk melakukan perikatan audit, jumlah aset dan jumlah pendapatan. Penelitian ini dilakukan dengan menyebarkan kuesionairs untuk Auditor responden yang bekerja di Jakarta, baik dari empat besar dan empat non besar. Data yang diterima adalah 46 dari 50 responden. Bentuk pengujian hasil regresi menunjukkan bahwa satu variabel independen, yaitu waktu yang dibutuhkan untuk melakukan perikatan audit, yang mempengaruhi audit sistem informasi dilaksanakan oleh Auditor.
\end{abstract}

Kata kunci: audit sistem informasi, penentuan risiko, ukuran Kantor Akuntan Publik, kompleksitas bisnis, kompleksitas informasi sysem, waktu, jumlah aset, jumlah pendapatan.

\section{PENDAHULUAN}

Pada era globalisasi sekarang ini, perangkat teknologi informasi (TI) berkembang begitu cepat. Penggunaan TI ini berdampak pada cara kerja auditor dalam memberikan pelayanan jasanya kepada perusahaan yang menjadi kliennya. Auditor harus melakukan penyesuaian prosedur audit terhadap klien yang memiliki TI, yaitu penilaian resiko pengendalian klien terhadap sistem TI yang digunakannya dan pengumpulan bukti audit yang tidak lagi di dalam bentuk kertas tetapi dalam bentuk data yang terdapat di komputer. 
Statement on Auditing Standards (SAS) no. 94 (AICPA 2001) menyarankan bahwa seorang auditor sistem informasi dapat ditugaskan dalam audit yang melingkupi lingkungan komputerisasi intensif. Auditor sistem informasi dapat meningkatkan sumber bukti bagi auditor dalam lingkungan Sistem Informasi yang kompleks (POB 2000, AICPA 2001).

SAS 94 juga mengingatkan auditor bahwa penilaian terhadap resiko pengendalian pada tingkat maksimum dan mengandalkan hanya pada substantif test mungkin tidak efektif bagi klien dengan lingkungan IT yang kompleks (AICPA 2001). Auditor disarankan untuk mempertimbangkan penggunaan prosedur audit terkait komputer, termasuk spesialis IT, ketika auditor memperoleh pemahaman mengenai pengendalian internal klien selama perencanaan audit (AICPA 2008, AU 319.29-32). Kemudian, PCAOB (Public Company Accounting Oversight Board's Auditing Standard) No. 5 mengharuskan auditor perusahaan untuk menyatakan suatu opini mengenai efektivitas dari sistem internal control perusahaan pada laporan keuangan (PCAOB 2007).

Kemajuan TI yang dimiliki klien sangat cepat sehingga mengubah cara auditor dalam melakukan pekerjaannya yaitu dengan menggunakan prosedur audit berbasis TI. Apa yang menjadi faktor yang mempengaruhi penggunaan prosedur audit berbasis TI merupakan hal yang akan diteliti. Faktor tersebut diuji dalam penelitian ini, antara lain penilaian resiko pengendalian klien, ukuran kantor akuntan publik (KAP), kompleksitas bisnis, kompleksitas sistem informasi, lama audit, jumlah aset dan jumlah pendapatan.

Penelitian ini dibatasi agar penelitian ini dapat dilakukan sebaik dan seefektif mungkin. Data mengenai penelitian ini, diperoleh dari penyebaran 50 kuesioner yang disebarkan kepada auditor yang bekerja di KAP di Jakarta. Pemilihan KAP di Jakarta dilakukan secara acak dan terbatas agar penelitian dapat fokus ke hal yang akan diteliti. Meskipun dilakukan secara acak, pengambilan data yaitu kuesioner akan didistribusikan ke KAP yang memiliki sifat yang dapat mewakili (representative) antara KAP yang berafiliasi dengan Big Four dan Non Big Four.

Pertimbangan yang dilakukan auditor mencakup banyak hal. Penelitian ini meneliti faktor apa saja yang perlu dipertimbangkan oleh auditor dalam mengambil keputusan apakah perlu dipakai teknologi informasi dalam mengaudit perusahaan. Faktor yang dapat menjadi penentu adalah penilaian risiko pengendalian yang terdapat di perusahaan apakah rendah atau tinggi, besarnya kantor akuntan publik yang dipakai perusahaan, kompleksitas bisnis perusahaan yang diaudit, kompleksitas sistem informasi yang dimiliki perusahaan, lama waktu audit yang dilakukan, serta besarnya perusahaan yang dapat diukur dari jumlah asset dan jumlah pendapatan.

\section{KAJIAN TEORI}

Menurut Hall dan Singleton (2005: 3) definisi auditing adalah:

"Auditing is a systematic process of objectively obtaining and evaluating evidence regarding assertions about economic actions and events to ascertain the degree of correspondence between those assertions and establishing criteria and communicating the result to interested users."

Menurut Agoes (2004:3) pengertian auditing adalah:

"Suatu pemeriksaan yang dilakukan secara kritis dan sistimatis, oleh pihak yang independen, terhadap laporan keuangan yang telah disusun oleh manajemen, beserta 
catatan-catatan pembukuan dan bukti-bukti pendukungnya, dengan tujuan untuk dapat memberikan pendapat mengenai kewajaran laporan keuangan tersebut.”

Menurut Weber (1999), "Information System Audit is the process of collecting and evaluating evidence to determine whether computer system safeguards assets, maintains data integrity, allows organizational goals to be achieved effectively, and uses resources efficiently".

Agoes (2004) menerangkan bahwa ada dua metode yang bisa dilakukan auditor dalam audit sistem informasi yaitu audit around the computer dan audit through the computer. Audit around the computer hanya memeriksa input dan output dari proses pengolahan data berbantuan sistem informasi, tanpa memeriksa sistem yang digunakan tersebut. Audit through the computer sebaliknya menguji sistem yang digunakan oleh perusahaan dalam mengolah datanya. Caranya dapat dilakukan dengan memakai Generalized Audit Software (GAS).

Gondodiyoto (2007) membagi audit sistem informasi menjadi 2, yaitu audit sistem informasi yang dilaksanakan dalam rangka audit laporan keuangan dan audit sistem informasi yang dilakukan dalam kaitannya dengan IT Governance.

Standar Audit Sistem Informasi. Standar audit bagi auditor di Indonesia diatur oleh Ikatan Akuntan Indonesia dalam Standar Profesional Akuntan Publik yang berisi:

Standar Umum: (1) Audit harus dilaksanakan oleh seorang atau lebih yang memiliki keahlian dan pelatihan teknis yang cukup sebagai auditor; (2) Dalam semua hal yang berhubungan dengan penugasan, independensi dalam sikap mental harus dipertahankan oleh auditor; (3) Dalam pelaksanaan audit dan penyusunan pelaporannya, auditor wajib menggunakan kemahiran profesionalnya dengan cermat dan seksama

Standar Pekerjaan Lapangan: (1) Pekerjaan harus direncanakan sebaik-baiknya dan jika digunakan asisten harus disupervisi dengan semestinya; (2) Pemahaman yang memadai atas struktur pengendalian intern harus diperoleh untuk merencanakan audit dan menentukan sifat, saat, dan lingkup pengujian yang akan dilakukan; (3) Bukti audit kompeten yang memadai harus diperoleh melalui inspeksi, pengamatan pengajuan pertanyaan, dan konfirmasi sebagai dasar yang memadai untuk menyatakan pendapat atas laporan keuangan hasil audit.

Standar Pelaporan: (1) Laporan audit harus menyatakan apakah laporan keuangan telah disusun sesuai dengan prinsip akuntansi yang berlaku umum; (2) Laporan audit harus menunjukkan keadaan yang di dalamnya prinsip akuntansi tidak secara konsisten diterapkan ke dalam penyusunan laporan keuangan periode berjalan yang sesuai dengan prinsip akuntansi yang berlaku umum; (3) Pengungkapan informasi dalam laporan keuangan harus dipandang memadai, kecuali dinyatakan lain dalam laporan audit; (4) Laporan audit harus memuat pernyataan pendapat mengenai laporan keuangan secara keseluruhan atau asersi bahwa pernyataan demikian tidak dapat diberikan. Jika pendapat secara keseluruhan tidak dapat diberikan, maka alasannya harus dinyatakan. Dalam semua hal yang nama auditor dikaitkan dengan laporan keuangan, auditor harus memuat petunjuk yang jelas mengenai sifat pekerjaan auditor, jika ada, dan tingkat tanggung jawab auditor yang bersangkutan."

Audit sistem informasi juga berdasarkan standar audit yang telah ditetapkan, khususnya lagi dipakai: (1) PSA No.57 mengenai audit dalam lingkungan sistem berbasis komputer; (2) PSA No.59 mengenai teknik audit berbantuan komputer; (3) PSA No.63 mengenai lingkungan sistem informasi komputer; (4) PSA No.64 mengenai lingkungan 
sistem informasi komputer secara online; (5) PSA No.65 mengenai lingkungan sistem informasi komputer dengan sistem database.

ISACA (Information System Audit and Control Association) mengeluarkan Information System Auditing Standards and Guideliness yang berisi standar dan panduan dalam melaksanakan audit berbasis sitem informasi yang berlaku secara internasional. ITGI (Information Technology Governance Institute) mengeluarkan panduan bagi tata kelola sistem informasi yang juga dapat dipakai oleh auditor sistem informasi. Panduan tersebut dinamakan CObIT (Control Objectives for Information and related Technology).

Penelitian Terdahulu. Diketahui bahwa pada beberapa penelitian sebelumnya yang dilakukan oleh Bedard (1989), Elder dan Allen (1994), Johnstone dan Bedard (2001), dalam Janvrin, Bierstaker, dan Lowe (2009) dan Mock dan Wright (1993 dan 1999), menyatakan secara spesifik bahwa penilaian risiko pengendalian memiliki pengaruh yang tidak signifikan terhadap perencanaan audit.

Penelitian lainnya yang dilakukan oleh Wright (1988) menunjukan hal yang berbeda yaitu perencanaan pengumpulan bukti disesuaikan dengan adanya kenaikan risiko. Begitu juga oleh Bierstaker dan Wright (2005), menunjukan bahwa ada interaksi yang besar antara penilaian risiko dengan penyesuaian perencanaan audit.

Penelitian yang dilakukan oleh Jenvrin, Bierstaker, dan Lowe (2009) menunjukan bahwa ada pengaruh yang signifikan antara tingkat penilaian risiko yang dilakukan oleh auditor terhadap penggunaan prosedur audit yang terkait dengan komputer, di mana auditor yang melakukan tingkat penilaian risiko di bawah maksimum tiga kali lebih menyukai penggunaan prosedur audit terkait komputer pada klien yang memiliki tingkat bisnis berbasis TI yang cukup kompleks.

Penelitian yang dilakukan oleh Gist dan Davidson (1999) dan Palmrose (1986) menunjukan bahwa perusahaan audit yang lebih besar memiliki sumber daya yang lebih besar untuk digunakan dan memiliki basis operasi yang lebih luas sehingga harus bisa menyesuaikan diri lebih baik dengan kebutuhan klien dibandingkan perusahaan audit yang lebih kecil. Ini dapat menjelaskan bahwa perusahaan audit yang lebih besar dapat memberikan pelatihan audit TI kepada auditornya dan dengan lebih baik dalam penggunaan prosedur audit berbasis TI. Perusahaan audit yang lebih besar lebih bisa menyesuaikan prosedur auditnya untuk mengikuti perkembangan klien yang juga menggunakan prosedur bisnis terkomputerisasi.

Hipotesis. Ada tujuh hipotesis yang dapat dirumuskan dalam penelitian ini, yaitu:

H1 : Terdapat pengaruh yang signifikan antara penilaian risiko pengendalian terhadap pelaksanaan audit berbasis TI.

H2 : Terdapat pengaruh yang signifikan antara ukuran KAP terhadap pelaksanaan audit berbasis TI.

H3 : Terdapat pengaruh yang signifikan antara kompleksitas bisnis terhadap pelaksanaan audit berbasis TI.

H4 : Terdapat pengaruh yang signifikan antara kompleksitas sistem informasi terhadap pelaksanaan audit berbasis TI.

H5 : Terdapat pengaruh yang signifikan antara lama audit terhadap pelaksanaan audit berbasis TI.

H6 : Terdapat pengaruh yang signifikan antara jumlah aset terhadap pelaksanaan audit berbasis $\mathrm{TI}$. 
H7 : Terdapat pengaruh yang signifikan antara jumlah pendapatan terhadap pelaksanaan audit berbasis TI

\section{METODE}

Metode Penarikan Sampel dan Pengumpulan Data. Populasi dari penelitian ini adalah KAP Big Four dan KAP non Big Four yang ada di Jakarta. Sedangkan sampel dari penelitian ini adalah individual auditor yang dianggap dapat mewakili keseluruhan auditor yang ada di Indonesia. Metode yang digunakan dalam penarikan sampel ini adalah purposive random sampling. Purposive random sampling adalah suatu metode penarikan sampel yang dilakukan dengan memilih secara acak responden tetapi tetap memiliki keterwakilan karakteristik yang homogen.

Data yang diperlukan dalam penelitian ini diperoleh dengan menyebarkan kuesioner kepada 50 auditor di beberapa KAP sehingga dapat disimpulkan bahwa data merupakan data primer. Data yang diperoleh dari kuesioner secara garis besar terdiri dari demografik dan karakteristik TI klien termasuk di dalamnya variabel yang digunakan dalam penelitian.

Identifikasi Variabel. Di dalam suatu penelitian diperlukan suatu konsep yang benilai yang diteliti yang disebut variabel. Variabel yang ada di penelitian ini seperti terlihat pada kerangka pemikiran dapat dikelompokan sebagai variabel dependen dan variabel independen.

Variabel dependen adalah variabel yang tergantung atau dipengaruhi oleh variabel lainnya. Dalam penelitian ini, pelaksanaan audit berbasis TI bertindak sebagai variabel dependen. Sedangkan variabel independen adalah variabel yang mempengaruhi variabel dependen dan tidak terikat variabel manapun. (1) Variabel Dependen. Seperti telah dijelaskan di atas, yang bertindak sebagai variabel dependen dalam penelitian ini adalah pelaksanaan audit berbasis TI. Pelaksanaan audit berbasis TI akan terlihat dari hasil penyebaran kuesioner kepada auditor di beberapa KAP. Pengukuran untuk variabel dependen ini dengan cara menghitung jumlah jawaban 'ya' dalam prosedur audit berbasis TI. (2) Variabel Independen. Variabel independen yang digunakan dalam penelitian ini adalah: (a) Risiko pengendalian. Variabel ini dikategorikan ke tiga tingkat yaitu penilaian risiko audit di tingkat yang Much Greater Than Normal (MGTN), Greater Than Normal (GTN) dan penilaian risiko audit di tingkat Normal (N). Variabel ini merupakan variabel dummy. Jika auditor dalam melakukan penilaian menetapkan risiko pengendalian klien berada di $\mathrm{N}$ akan diberi kode 1 , di tingkat resiko GTN akan diberi kode 2, sedangkan di tingkat MGTN akan diberi kode 3. Adapun maksud dari penilaian risiko audit $\mathrm{N}$ adalah auditor mempercayai bahwa penugasan yang terkait dengan audit berbasis teknologi informasi adalah penugasan yang resikonya normal . Sedangkan penilaian risiko audit yang berada di tingkat yang GTN adalah auditor mendapat keyakinan bahwa penugasan yang diterimanya di tingkat diatas normal, misalnya untuk klien yang biasanya adalah klien yang memerlukan tanggung jawab publik yang besar. Sedangkan untuk risiko audit MGTN adalah penugasan yang diterimanya adalah berisiko diatas GTN dan menjadi sorotan publik. (b) Ukuran KAP. Variabel ini merupakan variabel dummy. Untuk KAP yang berafiliasi dengan KAP internasional (Big Four) akan diberi kode 0, sedangkan KAP lainnya di luar big four akan diberi kode 1. (c) Kompleksitas bisnis. Jenis perusahaan manufaktur diberi kode 0 , sedangkan selain manufaktur diberi kode 1 . Perusahaan selain 
manufaktur dikategorikan sebagai jenis perusahaan yang lebih kompleks karena memerlukan teknologi informasi yang berbeda dengan perusahaan umumnya seperti manufaktur. (d) Kompleksitas sistem informasi. Pengukuran kompleksitas sistem informasi dibagi menjadi sederhana, sedang dan kompleks. Sistem informasi yang sederhana diberi nilai 1 , sedang diberi nilai 2, dan kompleks diberi nilai 3. (e) Lama audit. Lama audit merupakan lamanya audit yang dilaksanakan yang diukur dari jumlah minggu dalam melakukan audit. 0-3 minggu diberi nilai 1, 4-8 minggu diberi nilai 2, dan lebih dari 8 diberi nilai 3. (f) Jumlah asset. Diukur dari jumlah aset $<10$ miliar diberi nilai $1,10-100$ miliar diberi nilai 2, >100 miliar diberi nilai 3. (g) Jumlah pendapatan. Diukur dari jumlah pendapatan $<2$ miliar diberi nilai 1, 2-10 miliar diberi nilai 2, dan >10 miliar diberi nilai 3 .

Model Penelitian. Persamaan regresi berganda dalam penelitian ini:

$$
\mathrm{Y}=\mathrm{a}+\mathrm{b} 1 \mathrm{x} 1+\mathrm{b} 2 \mathrm{x} 2+\mathrm{b} 3 \mathrm{x} 3+\mathrm{b} 4 \mathrm{x} 4+\mathrm{b} 5 \mathrm{x} 5+\mathrm{b} 6 \mathrm{x} 6+\mathrm{b} 7 \mathrm{x} 7+\mathrm{e}
$$

Keterangan: $\mathrm{Y}=$ pelaksanaan audit berbasis $\mathrm{TI} ; \mathrm{X} 1$ = penilaian risiko pengendalian; $\mathrm{X} 2$ = ukuran KAP; $\mathrm{X} 3=$ kompleksitas bisnis; $\mathrm{X} 4=$ kompleksitas sistem informasi; $\mathrm{X} 5=$ lama audit.; X6 = jumlah aset; X7 = jumlah pendapatan.

Teknik Pengolahan Data. Dalam penelitian ini digunakan uji validitas dan reliabilitas, uji asumsi klasik dan uji regresi linear berganda. Uji validitas dan reliabilitas digunakan untuk menguji keandalan dari pertanyaan kuesioner yang dibagikan. Ini diperlukan agar data yang didapat dari pendistribusian kuesioner dapat menghasilkan kesimpulan yang terbaik. Sedangkan uji asumsi klasik yang akan digunakan adalah uji normalitas, uji multikolinearitas, dan uji heteroskedastisitas. Uji normalitas digunakan untuk menguji apakah data terdistribusi secara normal. Uji multikolinearitas untuk menguji ada atau tidaknya korelasi antar variabel independen. Uji heteroskedastisitas untuk menguji apakah terjadi variance residual suatu periode pengamatan ke periode pengamatan yang lain.

Uji regresi linear berganda adalah uji yang berguna untuk mengukur hubungan fungsi antara satu variabel dependen dengan independen. Uji ini akan digunakan untuk melihat pengaruh variabel independen terhadap pelaksanaan audit berbasis TI.

\section{HASIL DAN PEMBAHASAN}

Responden dari penelitian ini telah direkapitulasi sehingga dapat memberikan gambaran mengenai karakteristik auditor (responden). Dari Tabel 1 mengenai karakteristik responden terlihat jumlah responden yaitu sebanyak 44 orang. 44 orang ini diharapkan dapat mewakili sifat dari auditor secara keseluruhan baik Big Four dan non Big Four.

Sebesar $79.55 \%$ responden merupakan auditor yang memegang pendidikan terakhir Strata 1. Kebanyakan dari responden belum memiliki sertifikasi, hanya $40.91 \%$ auditor memiliki sertifikasi CPA dan $4.54 \%$ memiliki sertifikasi lainnya. Mayoritas responden berjenis kelamin laki-laki (68.18\%). Sebanyak 68.18\% responden berasal dari KAP Big Four dan sebesar 31.82\% berasal dari KAP non Big Four.

Dilihat pada Tabel 2, menunjukan bahwa 70\% responden memiliki klien yang mempunyai rata-rata nilai aset di atas enam ratus milayar rupiah, $18 \%$ responden memiliki klien dengan rata-rata aset sebesar seratus hingga enam ratus milyar rupiah, sisanya memiliki klien dengan rata-rata nilai aset sebesar kurang dari seratus milyar rupiah. $80 \%$ responden memiliki klien yang mempunyai rata-rata pendapatan lebih dari seratus milyar rupiah, dan sisanya memiliki klien dengan rata-rata aset sebesar dua puluh hingga seratus milyar rupiah. 
Tabel 1. Karakteristik Responden

\begin{tabular}{|c|c|c|c|}
\hline & $\begin{array}{c}\text { Total } \\
\text { Responden }\end{array}$ & KAP BIG 4 & KAP Non BIG 4 \\
\hline \multicolumn{4}{|c|}{ Pendidikan Terakhir } \\
\hline \multirow[t]{2}{*}{ S1 } & 35 & 23 & 12 \\
\hline & [79.55\%] & [82.14\%] & {$[75.00 \%]$} \\
\hline \multirow[t]{2}{*}{$\geq \mathrm{S} 2$} & 9 & 5 & 4 \\
\hline & [20.45\%] & [17.86\%] & [25.00\%] \\
\hline \multicolumn{4}{|l|}{ Sertifikasi } \\
\hline \multirow[t]{2}{*}{ Belum Sertifikasi } & 24 & 5 & 19 \\
\hline & [54.55\%] & [29.41\%] & {$[70.37 \%]$} \\
\hline \multirow[t]{2}{*}{ CPA } & 18 & 10 & 8 \\
\hline & [40.91\%] & [58.82\%] & [29.63\%] \\
\hline Lainnya & $\begin{array}{r}2 \\
{[4.54 \%]}\end{array}$ & $\begin{array}{r}2 \\
{[11.76 \%]}\end{array}$ & $\begin{array}{r}0 \\
{[0 \%]}\end{array}$ \\
\hline \multicolumn{4}{|l|}{ Jenis Kelamin } \\
\hline \multirow[t]{2}{*}{ Laki-laki } & 30 & 22 & 8 \\
\hline & [68.18\%] & [75.86\%] & [53.33\%] \\
\hline \multirow[t]{2}{*}{ Perempuan } & 14 & 7 & 7 \\
\hline & [31.82\%] & [24.14\%] & [46.67\%] \\
\hline \multirow[t]{2}{*}{ Ukuran KAP } & 44 & 30 & 14 \\
\hline & & [68.18\%] & [31.82\%] \\
\hline \multirow[t]{2}{*}{$\begin{array}{l}\text { Apakah audit } \\
\text { menggunakan IT }\end{array}$} & 44 & 30 & 14 \\
\hline & & [68.18\%] & [31.82\%] \\
\hline
\end{tabular}

Tabel 2. Karakteristik Audit terhadap Klien

\begin{tabular}{llll}
\hline & \multicolumn{1}{c}{$\begin{array}{c}\text { Total } \\
\text { Responden }\end{array}$} & KAP Big Four & KAP Non Big Four \\
\hline Jumlah aset klien & 5 & 3 & 2 \\
$<$ Rp 100 miliar & {$[11 \%]$} & 10 & $14.29 \%$ \\
& 8 & 4 & 4 \\
Rp 100 - 600 Miliar & {$[18 \%]$} & $13.33 \%$ & $28.58 \%$ \\
& 31 & 23 & 8 \\
$>$ Rp 600 Miliar & {$[70 \%]$} & $76.66 \%$ & $57.14 \%$ \\
& & & \\
Jumlah pendapatan klien & 0 & 0 & 0 \\
$<$ Rp 20 miliar & {$[0 \%]$} & $0 \%$ & $0 \%$ \\
& 9 & 4 & 5 \\
Rp 20 -100 Miliar & {$[20 \%]$} & $13.33 \%$ & $29.41 \%$ \\
\hline
\end{tabular}


Kristian dan Imelda: Analisis Faktor Yang Memperngaruhi Pelaksanaan Audit...

\begin{tabular}{llll}
\hline & \multicolumn{1}{c}{$\begin{array}{c}\text { Total } \\
\text { Responden }\end{array}$} & KAP Big Four & \multicolumn{1}{c}{ KAP Non Big Four } \\
\hline$>$ Rp 100 Miliar & 35 & 26 & 12 \\
& {$[80 \%]$} & $86.67 \%$ & $70.59 \%$
\end{tabular}

Penilaian Risiko Pengendalian

$\begin{array}{llll}\text { Normal } & 36 & 26 & 10 \\ \text { Greater Than Normal } & {[81 \%]} & 86.67 \% & 71.43 \% \\ & 6 & 3 & 3 \\ \text { Much Greater Than Normal } & {[14 \%]} & 10.00 \% & 21.43 \% \\ & 2 & 1 & 1 \\ & {[5 \%]} & 3.33 \% & 7.14 \%\end{array}$

Waktu yang diperlukan untuk audit tahunan

\begin{tabular}{llll}
$0-3$ minggu & 0 & 0 & 0 \\
& {$[0 \%]$} & $0 \%$ & $0 \%$ \\
$4-8$ minggu & 24 & 21 & 3 \\
\multirow{3}{*}{ Lebih dari 8 minggu } & {$[55 \%]$} & $70.00 \%$ & $21.43 \%$ \\
& 20 & 9 & 11 \\
& {$[45 \%]$} & $30.00 \%$ & $78.57 \%$
\end{tabular}

Tingkat kompleksitas sistem informasi klien

\begin{tabular}{llll} 
sederhana & 2 & 1 & 1 \\
\multirow{3}{*}{ sedang } & {$[5 \%]$} & $3.33 \%$ & $7.14 \%$ \\
& 16 & 13 & 3 \\
kompleks & {$[36 \%]$} & $43.33 \%$ & $21.43 \%$ \\
& 26 & 16 & 10 \\
& {$[59 \%]$} & $53.33 \%$ & $71.43 \%$
\end{tabular}

Jenis Industri

Dagang atau manufaktur $\quad 36$

$36 \quad 27 \quad 9$

[82\%] $\quad 90.00 \% \quad 64.29 \%$

Non dagang 8

$3 \quad 5$

Apakah auditor

[18\%] $\quad 10.00 \% \quad 35.71 \%$

menggunakan komputer dalam bekerja dan memiliki klien yang dalam proses bisnisnya menggunakan teknologi informasi

\begin{tabular}{llll} 
Ya & 44 & 30 & 14 \\
& {$[100 \%]$} & $68.18 \%$ & $31.82 \%$ \\
Tidak & 0 & 0 & 0 \\
& {$[0 \%]$} & $0 \%$ & $0 \%$ \\
\hline
\end{tabular}


Sekitar 59\% responden memiliki klien yang mempunyai sistem informasi yang dipakai sangat kompleks. Sekitar 81\% responden menilai risiko pengendalian adalah Normal, ketika memeriksa klien yang memiliki teknologi informasi di dalamnya, Sekitar 14\% responden menilai risiko pengendalian adalah Greater Than Normal, sedangkan sisanya menilai risiko pengendalian adalah Much Greater Than Normal, ketika memeriksa klien yang memiliki teknologi

Sebesar 55 \% memerlukan waktu sekitar empat sampai delapan minggu untuk melakukan audit terhadap klien, dan sisanya 45\% memerlukan waktu lebih dari delapan minggu untuk melakukan audit. Sebesar $82 \%$ responden memiliki klien di industri dagang atau manufaktur. Seluruh auditor (100\%) menggunakan komputer dalam bekerja dan memiliki klien yang dalam proses bisnisnya menggunakan teknologi informasi.

Seluruh responden memasukan pertimbangan teknologi informasi yang dimiliki klien ketika melakukan penilaian resiko, kemudian di dalam mendapatkan pemahaman mengenai proses dan sistem bisnis klien, auditor memeriksa transaksi yang signifikan yang mendukung laporan keuangan klien.

Sebanyak 98 \% responden menggunakan cara menguji prosedur dan catatan (baik otomatis maupun manual) tentang yang dimiliki klien. Sebanyak $98 \%$ responden lebih banyak menguji prosedur dan catatan (baik otomatis maupun manual) tentang bagaimana suatu transaksi dimulai, diproses, dan dilaporkan terutama untuk transaksi yang signifikan.

Di dalam menguji pengendalian otomatisasi komputer, 91\% responden menggunakan hal tersebut untuk menentukan bahwa fungsi pengendalian sudah sesuai dengan yang diharapkan. Sebanyak masing-masing 93\% responden memeriksa pengendalian komputer klien terhadap perubahan program yang terjadi, sedangkan 95\% responden mengevaluasi pengendalian akses masuk ke program klien dan pengendalian sistem software.

Sebanyak 66\% responden menggunakan CAAT untuk mendeteksi dan mengevaluasi risiko kecurangan, 70 \% untuk Mengidentifikasi journal entries dan jurnal penyesuaian untuk diuji, 73\% untuk memeriksa keakuratan data elektronik yang dimiliki klien, 64\% untuk melakukan reka ulang prosedur klien, 73\% untuk Memilih sampel transaksi, 75\% untuk mensortir transaksi berdasarkan spesifik karakteristik, 70\% untuk menguji keterwakilan populasi di dalam sampel dan mengevaluasi keefektifan pengendalian, 61\% untuk mengevaluasi keberadaan dan kelengkapan persediaan

Sebanyak 93\% responden selalu meminta klien untuk menyediakan catatan elektronik untuk membantu Auditor menjalankan substantive testing. Dari total 44 responden, hanya 59\% yang menggunakan jasa IT spesialis untuk membantu mereka dalam melakukan audit.

Dari 59\% tersebut, sebanyak 61\% responden menggunakan jasa IT specialist untuk meminta keterangan kepada IT klien bagaimana suatu sistem dan data diawali, dan diproses, serta untuk merencanakan pengujian terhadap pengendalian teknologi informasi klien. Dan dari 59\% responden yang menggunakan jasa tersebut sebesar 64\%-nya menggunakan jasa IT spesialis untuk menginspeksi dokumentasi sistem klien dan mengamati operasi pengendalian klien. Dari 59\% responden yang menggunakan jasa tersebut sebesar 52\%-nya menggunakan jasa IT spesialis untuk merencanakan dan melakukan uji performa terhadap pengendalian IT.

Pengujian Validitas dan Reliabilitas. Syarat mutlak dari setiap instrument yang digunakan untuk memperoleh data penelitian adalah valid dan reliable. Suatu instrument dinyatakan valid bila instrument itu dapat mengukur apa yang dimaksud untuk diukur 
instrumen itu. Suatu instrument dinyatakan reliable bila instrument itu digunakan sebanyak dua kali untuk mengukur hal yang sama dari subyek yang sama menghasilkan hasil yang (relatif) sama. Pengujian validitas dan reliabilitas digunakan untuk menguji keandalan dari pertanyaan kuesioner yang dibagikan. Ini diperlukan agar data yang didapat dari hasil pendistribusian kuesioner dapat menghasilkan kesimpulan yang terbaik.

Syarat suatu instrumen penelitian dikatakan valid apabila nilai Corrected Item Total Correlation > 0.3 (Kaplan, 2003:141). Sedangkan suatu instrumen penelitian dikatakan reliabilitas dinilai berdasarkan nilai Cronbach's Alphanya yang harus lebih besar sama dengan dari 0.7 (Kaplan, 2003:126). Berikut ini disajikan hasil pengujian validitas yang dilanjutkan dengan pengujian reliabilitas menggunakan SPSS 16.0.

Tabel 3. Uji validitas dan Reliabilitas

Scale: All Variables

Case Processing Summary

\begin{tabular}{llrr}
\hline & & $\mathrm{N}$ & \multicolumn{2}{c}{$\%$} \\
\hline Cases & Valid & 44 & 100.0 \\
& Excluded $^{\mathrm{a}}$ & 0 & .0 \\
& Total & 44 & 100.0 \\
\hline
\end{tabular}

a. Listwise deletion based on all variables in the procedure.

Tabel 4. Reliability Statistics

\begin{tabular}{crr}
\hline Cronbach's Alpha & \multicolumn{2}{c}{ N of Items } \\
\hline & .947 & 14 \\
\hline
\end{tabular}

Uji validitas yang dilakukan adalah menguji pertanyaan untuk variabel Y karena tiap variabel $\mathrm{X}$ hanya diukur dari 1 pertanyaan. Variabel $\mathrm{Y}$ adalah pertanyaan- pertanyaan untuk menilai faktor yang mempengaruhi pelaksanaan audit berbasis TI. Dari 26 pertanyaan, yang valid adalah 14 pertanyaan, sehingga dipakai 14 pertanyaan. Dari Tabel di atas juga dapat dilihat hasil uji reliabilitas, di mana pengukuran korelasi antarjawaban. Pada program SPSS, metode ini dilakukan dengan metode Cronbach Alpa, dimana suatu kuesioner dinyatakan reliabel bila nilai Cronbach Alpha lebih besar dari 0.7 (Kaplan, 2003:126).

Terlihat dari hasil pengujian di atas pada Tabel 3 bahwa keempat belas pertanyaan telah valid. Sebelumnya terdapat 12 butir pertanyaan ada yang di keluarkan tidak valid, yaitu: (a) butir pertanyaan pertama (penilaian resiko ketika memasukkan pertimbangan teknologi informasi yang dimiliki klien); (b) butir pertanyaan kedua (pemahaman sistem dan proses bisnis klien - menguji transaksi yang signifikan yang mendukung laporan keuangan klien); (c) butir pertanyaan ketiga (pemahaman sistem dan proses bisnis klien menguji prosedur dan catatan (baik otomatis maupun manual) tentang bagaimana suatu transaksi dimulai, diproses, dan dilaporkan terutama untuk transaksi yang signifikan); (d) butir pertanyaan keempat (pemahaman sistem dan proses bisnis klien - menguji bagaimana sistem menangkap peristiwa dan kondisi (di luar transaksi) yang dapat memengaruhi laporan keuangan); (e) butir pertanyaan kelima (pemahaman sistem dan proses bisnis klien - Menguji proses yang digunakan untuk menyiapkan laporan keuangan klien); (f) butir pertanyaan keenam (pengendalian otomatisasi komputer - fungsi pengendalian sudah sesuai dengan fungsi yang diharapkan); (g) butir pertanyaan ketujuh 
(pengendalian otomatisasi komputer - fungsi pengendalian dapat berjalan efektif selama periode audit); (h) butir pertanyaan kedelapan (pengendalian otomatisasi komputer fungsi pengendalian terdapat kontrol terhadap aplikasi yang dipakai); (i) butir pertanyaan kesembilan (pengendalian komputer klien terhadap perubahan yang terjadi di dalam program); (j) butir pertanyaan kesepuluh (pengendalian komputer klien terhadap pengendalian akses untuk memasuki program; (k) butir pertanyaan kesebelas (pengendalian komputer klien terhadap sistem software); (l) butir pertanyaan ke dua puluh satu (meminta klien untuk menyediakan catatan elektronik untuk membantu auditor menjalankan substantive testing)

Terlihat dari Tabel 4 di atas, menunjukan alat ukur reliabilitas yaitu dengan menilai Cronbach's Alpha. Seperti yang telah dijelaskan sebelumnya bahwa suatu kuesioner dapat dikatakan reliabel dalam menjadi instrumen penelitian, nilai Cronbach's Alphanya haruslah lebih besar sama dengan dari 0.7. Penelitian yang dilakukan memiliki nilai Cronbach's Alpha sebesar 0.947. Ini menunjukan bahwa instrumen penelitian ini sudah dapat menjadi instrumen penelitian yang andal.

Uji Asumsi Klasik. Uji asumsi klasik terdiri dari empat macam uji yaitu uji normalitas, uji multikolinearitas, uji otokorelasi, dan uji heteroskedastisitas. Karena uji otokorelasi erat hubungannya dengan uji yang terdiri lebih dari satu periode pengamatan, maka yang dipakai pada penelitian ini adalah uji normalitas, uji multikolinearitas, dan uji heteroskedastisitas. Berikut adalah hasil dari pengujian asumsi klasik terhadap variabelvariabel yang digunakan dalam penelitian ini.

Tabel 5. Hasil Uji Normalitas

NPar Tests

One-Sample Kolmogorov-Smirnov Test

\begin{tabular}{llr}
\hline & & Unstandardized Residual \\
\hline $\mathrm{N}$ & & 44 \\
Normal Parameters & $\mathrm{a}, \mathrm{b}$ & .0000000 \\
& Sean & 3.84023105 \\
Most Extreme Differences & Absolute & .088 \\
& Positive & .059 \\
& Negative & -.088 \\
Kolmogorov-Smirnov Z & & .581 \\
Asymp. Sig. (2-tailed) & & .888 \\
\hline
\end{tabular}

a. Test distribution is Normal.

b. Calculated from data.

Besarnya nilai kolmogorov-Smirnov adalah 0.581 (Santoso, 2000:53). Nilai tersebut terletak pada rentang nilai yang telah ditetapkan sebesar lebih dari 0.05. Maka dapat diambil kesimpulan bahwa data berdistibusi normal telah terpenuhi.

Uji Multikolinearitas. Pengujian ini dilakukan untuk mengetahui ada atau tidaknya variabel independen yang memiliki hubungan dengan variabel independen lainnya dalam suatu model regresi. Apabila terdapat hubungan antar variabel independen dalam model tersebut, maka akan menyebabkan terjadinya korelasi yang kuat antara suatu variabel 
independen dengan variabel independen lainnya. Suatu model regresi dapat dianggap baik, apabila terbebas dari multikolinearitas.

Untuk mendeteksi ada atau tidaknya multikolinearitas di dalam model regresi yang akan dihasilkan dapat dilihat dari nilai tolerance, Condition Index(CI), dan Variance Inflation Factor (VIF). Menurut Nugroho (2005:28), suatu model dapat dikatakan bebas dari multikolinearitas apabila nilai tolerance tidak kurang dari 0.1, dan VIF tidak lebih dari 10. Hasil pengujian multikolinearitas dapat dilihat di Tabel 6.

Tabel 6. Uji Multikolinieritas

Regression

Variables Entered/Removed

\begin{tabular}{|c|c|c|c|}
\hline Model & Variables Entered & Variables Removed & Method \\
\hline 1 & X7, X3, X1, X2, X4, X5, X6 & \multicolumn{2}{|r|}{ Enter } \\
\hline a. All r & quested variables entered. & & \\
\hline
\end{tabular}

Coefficients $^{\mathrm{a}}$

\begin{tabular}{|c|c|c|c|c|c|c|c|c|}
\hline & & \multicolumn{2}{|c|}{$\begin{array}{l}\text { Unstandardized } \\
\text { Coefficients }\end{array}$} & \multirow{2}{*}{$\begin{array}{c}\begin{array}{c}\text { Standardized } \\
\text { Coefficients }\end{array} \\
\text { Beta } \\
\end{array}$} & \multirow[b]{2}{*}{$\mathrm{t}$} & \multirow[b]{2}{*}{ Sig. } & \multicolumn{2}{|c|}{$\begin{array}{l}\text { Collinearity } \\
\text { Statistics }\end{array}$} \\
\hline \multicolumn{2}{|c|}{ Model } & B & Std. Error & & & & Tolerance & VIF \\
\hline 1 & (Constant) & -8.388 & 7.015 & & -1.196 & .240 & & \\
\hline & $\mathrm{X} 1$ & .793 & 1.373 & .081 & .577 & .567 & .797 & 1.254 \\
\hline & $\mathrm{X} 2$ & -2.088 & 1.600 & -.193 & -1.304 & .200 & .720 & 1.388 \\
\hline & X3 & 1.898 & 1.941 & .145 & .978 & .335 & .714 & 1.400 \\
\hline & $\mathrm{X} 4$ & .785 & 1.430 & .091 & .549 & .587 & .578 & 1.731 \\
\hline & X5 & 6.028 & 1.735 & .595 & 3.473 & .001 & .536 & 1.865 \\
\hline & X6 & -.870 & 1.546 & -.118 & -.563 & .577 & .357 & 2.800 \\
\hline & $\mathrm{X} 7$ & .908 & 2.644 & .073 & .343 & .733 & .352 & 2.840 \\
\hline
\end{tabular}

a. Dependent Variable: Y

Dari Tabel 6 terlihat bahwa semua variabel X di regresi memiliki nilai VIF dibawah 10. Hal ini menunjukkan semua variabel $X$ telah bebas dari multikolinieritas yang berarti tidak ada hubungan di antara variabel $\mathrm{X}$.

Setelah pengujian asumsi klasik selesai dilakukan, maka selanjutnya akan dilakukan pengujian hipotesis yaitu dengan melakukan uji regresi linear. Secara umum, uji regresi ini bertujuan untuk mengetahui apakah ada hubungan atau pengaruh antara variabel independen dengan variabel dependennya dan untuk mendeteksi kemungkinan masingmasing variabel independen berpengaruh secara signifikan atau tidak terhadap variabel dependen. Dalam menguji hipotesis penelitian ini, uji regresi linear yang digunakan adalah uji regresi linear dengan variabel boneka (dummy variable). Uji regresi linear dengan variabel boneka digunakan dalam penelitian ini sesuai dengan karakteristik penelitian ini yaitu variabel independennya merupakan data-data kategori dan tidak memiliki nilai kuantitatif sehingga harus dikategorikan ke suatu angka agar memiliki nilai dan bisa diproses. Dalam penelitian ini, analisis regresi linear dengan variabel boneka terdiri dari satu variabel dependen yaitu prosedur audit berbasis teknologi informasi dan tujuh variabel independen yaitu penilaian resiko pengendalian dan ukuran kantor akuntan 
publik, kompleksitas bisnis, kompleksitas sistem informasi, lama waktu audit, jumlah asset klien, dan jumlah pendapatan klien.

Variabel dependen penilaian risiko pengendalian memiliki tiga penilaian yaitu " 1 " untuk kategori resiko normal (N); “2” untuk di kategori resiko Greater Than Normal (GTN) dan "3" kategori resiko Much Greater Than Normal (MGTN). Variabel dependen ukuran kantor akuntan publik memiliki dua variabel boneka "0" untuk KAP big four dan "1" untuk KAP non big four. Variabel dependen kompleksitas sistem informasi memberikan nilai " 1 " untuk bisnis klien yang sederhana, "2" untuk bisnis klien yang sedang dan " 3 " untuk bisnis klien yang kompleks. Variabel dependen kompleksitas bisnis memiliki dua variabel boneka, yang ini dilihat dari jenis perusahaan klien yang diaudit apakah perusahaan dagang atau non-dagang.

Variabel dependen lama waktu audit memiliki memberikan nilai “ 1 ” untuk lama audit 0-3 minggu, nilai " 2 ” untuk lama audit 3-8 minggu, dan nilai “3” untuk lebih dari 8 minggu. Variabel dependen jumlah asset klien memberikan nilai " 1 ” untuk asset di bawah 100 miliar, nilai '”2" untuk asset 100-600 miliar, dan nilai "3" untuk asset di atas 600 miliar. Variabel dependen jumlah pendapatan klien memberikan nilai " 1 " untuk pendapatan di bawah 20 miliar, nilai "2" untuk 20-100 miliar dan nilai "3" untuk di pendapatan di atas 100 miliar.

Pengujian hipotesis terhadap variabel dilakukan dengan menggunakan analisis statistik yang terdiri dari uji nilai $\mathrm{F}$, uji nilai t, dan uji koefisien menggunakan tingkat keyakinan $95 \%$ atau $\alpha$ sebesar 5\%. Dari hasil pengolahan data dengan menggunakan SPSS 17.0 diperoleh hasil sebagai berikut:

Tabel 7. Hasil Uji Regresi Berganda Regression

Variables Entered/Removed

\begin{tabular}{|c|c|c|c|}
\hline Model & Variables Entered & Variables Removed & Method \\
\hline 1 & $X 7, X 3, X 1, X 2, X 4, X 5, X 6^{a}$ & & Enter \\
\hline
\end{tabular}

Model Summary ${ }^{\mathrm{b}}$

\begin{tabular}{lrrrr}
\hline & & & \multicolumn{2}{c}{ Std. Error of the } \\
Model & $\mathrm{R}$ & $\mathrm{R}$ Square & Adjusted R Square & \multicolumn{2}{c}{ Estimate } \\
1 & $.659^{\mathrm{a}}$ & .434 & .324 & 4.19701 \\
\hline
\end{tabular}

a. Predictors: (Constant), X7, X3, X1, X2, X4, X5, X6

b. Dependent Variable: $\mathrm{Y}$

\begin{tabular}{llrrrrr}
\multicolumn{7}{c}{ ANOVA $^{\mathrm{b}}$} \\
\hline \multirow{2}{*}{ Model } & & Sum of & & & & \\
\hline 1 & Squares & df & Mean Square & \multicolumn{1}{c}{ F } & Sig. \\
\hline & Regression & 485.749 & 7 & 69.393 & 3.939 & $.003^{\mathrm{a}}$ \\
& Residual & 634.137 & 36 & 17.615 & & \\
& Total & 1119.886 & 43 & & & \\
\hline
\end{tabular}

a. Predictors: (Constant), X7, X3, X1, X2, X4, X5, X6

b. Dependent Variable: $\mathrm{Y}$ 


\begin{tabular}{|c|c|c|c|c|c|c|}
\hline & \multicolumn{6}{|c|}{ Coefficients $^{\mathrm{a}}$} \\
\hline & & \multicolumn{2}{|c|}{$\begin{array}{l}\text { Unstandardized } \\
\text { Coefficients }\end{array}$} & \multirow{2}{*}{$\begin{array}{c}\text { Standardized } \\
\text { Coefficients } \\
\text { Beta }\end{array}$} & \multirow[b]{2}{*}{$\mathrm{t}$} & \multirow[b]{2}{*}{ Sig. } \\
\hline \multicolumn{2}{|c|}{ Model } & $\mathrm{B}$ & Std. Error & & & \\
\hline \multirow[t]{8}{*}{1} & (Constant) & -8.388 & 7.015 & & -1.196 & .240 \\
\hline & $\mathrm{X} 1$ & .793 & 1.373 & .081 & .577 & .567 \\
\hline & $\mathrm{X} 2$ & -2.088 & 1.600 & -.193 & -1.304 & .200 \\
\hline & X3 & 1.898 & 1.941 & .145 & .978 & .335 \\
\hline & X4 & .785 & 1.430 & .091 & .549 & .587 \\
\hline & X5 & 6.028 & 1.735 & .595 & 3.473 & .001 \\
\hline & X6 & -.870 & 1.546 & -.118 & -.563 & .577 \\
\hline & X7 & .908 & 2.644 & .073 & .343 & .733 \\
\hline
\end{tabular}

a. Dependent Variable: Y

Dimana: $\mathrm{X} 1$ = penilaian risiko pengendalian; $\mathrm{X} 2=$ ukuran KAP; $\mathrm{X} 3=$ kompleksitas bisnis; X4 = kompleksitas sistem informasi; X5 = lama audit; X6 = jumlah asset; X7 = jumlah pendapatan

Dengan melihat tabel di atas, maka dapat didapatkan persamaan regresi berganda sebagai berikut:

$\mathrm{Y}=\mathrm{a}+\mathrm{b} 1 \mathrm{x} 1+\mathrm{b} 2 \mathrm{x} 2+\mathrm{b} 3 \mathrm{x} 3+\mathrm{b} 4 \mathrm{x} 4+\mathrm{b} 5 \mathrm{x} 5+\mathrm{b} 6 \mathrm{x} 6+\mathrm{b} 7 \mathrm{x} 7+\mathrm{e}$

$\mathrm{Y}=-8,338+0,793 \mathrm{X} 1-2,088 \mathrm{X} 2+1,898 \mathrm{X} 3+0,785 \mathrm{X} 4+6,028 \mathrm{X} 5-0,870 \mathrm{X} 6+0,908$

$\mathrm{X} 7$

Di mana: $\mathrm{Y}=$ pelaksanaan audit berbasis TI; X1 = penilaian risiko pengendalian; $\mathrm{X} 2=$ ukuran KAP; X3 = kompleksitas bisnis; X4 = kompleksitas sistem informasi; X5 = lama audit.; X6 = jumlah aset; X7 = jumlah pendapatan.

Hasil pengujian regresi berganda menghasilkan penolakan Ha1 sehingga penilaian risiko pengendalian tidak mempengaruhi pelaksanaan audit berbasis teknologi informasi secara signifikan. Hal ini dapat dilihat dari nilai sig 0,567 yang lebih besar daripada 0,05. Tingkat risiko pengendalian akan mempengaruhi besarnya subtantif tes yang perlu dilakukan oleh auditor, namun tidak mempengaruhi apakah audit akan memakai teknologi informasi atau tidak.

Hipotesis alternatif kedua juga ditolak dari hasil regresi berganda. Hal ini dapat dilihat dari nilai sig 0,002, yang lebih besar dari alpha 0,05. Ukuran KAP tidak mempengaruhi audit berbasis teknologi informasi secara signifikan. Hal ini dapat disebabkan karena sedikitnya KAP non big four yang memakai audit berbasis teknologi informasi sehingga responden yang diperoleh tidak berimbang.

Hipotesis alternatif ketiga menguji apakah kompleksitas bisnis mempengaruhi penggunaan audit berbasis teknologi informasi secara signifikan. Hasil pengujian membuktikan bahwa kompleksitas bisnis tidak mempengaruhi penggunaan audit berbasis teknologi informasi secara signifikan dengan nilai sig 0,335. Hal ini menunjukkan bahwa bidang usaha perusahaan klien yang diaudit tidak menentukan apakah perlu memakai audit berbasis teknologi informasi atau tidak. Semua bidang usaha klien memiliki kemungkinan memakai audit berbasis teknologi informasi.

Hipotesis alternatif keempat menguji apakah kompleksitas sistem informasi mempengaruhi penggunaan audit berbasis teknologi informasi secara signifikan. Hasil 
pengujian membuktikan bahwa kompleksitas sistem informasi tidak mempengaruhi penggunaan audit berbasis teknologi informasi secara signifikan dengan nilai sig 0,587. Hal ini dapat disebabkan karena kebanyakan perusahaan di Indonesia tidak memakai sistem informasi khususnya sistem informasi akuntansi yang terintegrasi. Kebanyakan masih mencampur dengan sistem informasi berbasis komputer yang berbeda untuk tiap keperluan dan masih ada yang mencampurnya dengan sistem informasi manual.

Hasil pengujian hipotesis alternatif kelima mendukung lamanya audit mempengaruhi audit berbasis teknologi informasi. Nilai signifikansi sebesar 0,001 lebih kecil dari 0,05. Audit dengan durasi yang lama dapat menunjukkan adanya internal control yang lemah sehingga dibutuhkan audit berbantuan teknologi informasi.

Hipotesis alternatif keenam dan ketujuh ingin membuktikan apakah besarnya perusahaan mempengaruhi penggunaan audit berbasis informasi secara signifikan. Kedua hipotesis ini juga tidak diterima. Hipotesis keenam dengan memakai jumlah asset menghasilkan nilai sig 0,577. Hipotesis ketujuh dengan memakai jumlah pendapatan menghasilkan nilai sig 0,733. Hal ini menunjukkan bahwa skala perusahaan baik yang besar maupun kecil tidak mempengaruhi pertimbangan auditor untuk memakai audit berbantuan teknologi informasi atau tidak. Perusahaan besar maupun kecil sama-sama memiliki kesempatan diaudit dengan bantuan teknologi informasi.

Nilai adjusted $\mathrm{R}$ square dari regresi berganda sebesar 0,324. Hal ini berarti bahwa ketujuh variabel independen mempengaruhi variabel dependen secara bersama-sama sebesar $32,4 \%$. Sisanya $67,6 \%$ dari pertimbangan pemakaian audit berbasis teknologi informasi dipengaruhi oleh faktor lain.

Uji F menunjukkan nilai sig 0,03. Hal ini menunjukkan bahwa ketujuh variabel independen secara bersama-sama mempengaruhi variabel dependen. Hal ini juga berarti bahwa persamaan regresi berganda tersebut valid dan dapat dipakai.

\section{PENUTUP}

Penelitian ini menguji pengaruh tujuh faktor independen yaitu penilaian resiko pengendalian dan ukuran kantor akuntan publik, kompleksitas bisnis, kompleksitas sistem informasi, lama waktu audit, jumlah asset klien, dan jumlah pendapatan klien terhadap variabel dependen yaitu pelaksanaan audit berbasis teknologi informasi.

Variabel dependen penilaian risiko pengendalian memiliki tiga penilaian yaitu kategori resiko normal (N), resiko Greater Than Normal (GTN) dan resiko Much Greater Than Normal (MGTN). Variabel dependen ukuran kantor akuntan publik memiliki dua kategori penilaian yaitu KAP big four dan KAP non big four. Variabel dependen kompleksitas sistem informasi diukur oleh bisnis klien yang sederhana, bisnis klien yang sedang dan bisnis klien yang kompleks. Variabel dependen kompleksitas bisnis memiliki dua variabel boneka, yang ini dilihat dari jenis perusahaan klien yang diaudit apakah perusahaan dagang atau non-dagang.

Variabel dependen lama waktu audit memiliki tiga penilaian yaitu lama audit 0-3 minggu, 3-8 minggu, dan lebih dari 8 minggu. Variabel dependen jumlah asset klien memiliki tiga kategori penilaian yaitu asset di bawah 100 miliar, asset 100-600 miliar, dan asset di atas 600 miliar. Variabel dependen jumlah pendapatan klien memiliki 3 kategori penilaian yaitu pendapatan di bawah 20 miliar, pendapatan antara 20-100 miliar dan pendapatan di atas 100 miliar. 
Pengujian hipotesis terhadap variabel dilakukan dengan menggunakan analisis statistik yang terdiri dari uji nilai $\mathrm{F}$, uji nilai t, dan uji koefisien menggunakan tingkat keyakinan 95\% atau $\alpha$ sebesar 5\%. Pengolahan data dengan menggunakan SPSS 17.0 dan Excel 2007. Uji F menghasilkan nilai sig 0,03 yang berarti ketujuh variabel independen secara bersama-sama mempengaruhi variabel dependen secara signifikan.

Dari ketujuh hipotesis alternatif yang dibentuk, hanya variabel lamanya audit yang mempengaruhi pelaksanaan audit berbasis teknologi informasi. Sedangkan variabel penilaian risiko pengendalian, ukuran KAP, kompleksitas bisnis, kompleksitas sistem informasi, jumlah asset dan jumlah pendapatan tidak mempengaruhi secara signifikan terhadap pelaksanaan audit berbasis teknologi informasi. Hal ini dapat disebabkan karena belum adanya standarisasi faktor apa saja yang perlu dipertimbangkan auditor untuk melihat apakah audit yang sedang dijalankan perlu bantuan teknologi informasi. Oleh karena itu setiap KAP mengembangkan metodologinya masing-masing sehingga berbeda satu sama lain.

\section{DAFTAR RUJUKAN}

Agoes, Sukrisno, (2004) Auditing (Pemeriksaan Akuntan) oleh Kantor Akuntan Publik. Jakarta: Lembaga Penerbit Fakultas Ekonomi Universitas Indonesia.

Bierstaker, J., and A. Wright. (2005) The Interaction Between Auditor's risk Perceptions and Partner Preferences on Audit Program Planning. Advance in Accounting 21.

Gist, W.E., and R.A Davidson. (1999) "An Explanatory Study of the Influence of Client Factor on Audit Time Budget Variance”. Auditing: A Journal of Practice \& Theory 18.

Hall, J., and A. Singleton, (2005) Information Technology Auditing and Assurance $2^{\text {nd }}$ Edition. Thomson South Western, America.

Janvrin, D., J. Bierstaker, and D.J. Lowe, (2009) “An Investigation of Factors Influencing the Use of Computer-Related Audit Procedures”. Journal of Information System Vol $23(1)$.

Mock,T., and A. Wright. (1999) “An Explanatory Study of Auditor Evidential Planning Judgesment”. Auditing: A Journal of Practice and Theory 12

- (1993) Are Audit Program Plan Risk-Adjusted? Auditing: A Journal of Practice and Theory 18.

Palmrose, Z.V, (1986) “Audit fees and auditor size: Further Evidence”, Journal of Accounting Research, 24 (spring).

Wright, A. (1988) “The Impact of Prior Working Papers in Auditor Evidential Planning Judgements”. Accounting, Organizations and Society. 